\title{
Autologous Cytoplasmic Activated PD-1 CAR T-cells
}

National Cancer Institute

\section{Source}

National Cancer Institute. Autologous Cytoplasmic Activated PD-1 CAR T-cells. NCI

Thesaurus. Code C158599.

A preparation of autologous T-lymphocytes engineered to express a chimeric antigen receptor (CAR) specific for the tumor-associated antigen (TAA) cluster of differentiation 19 (CD19), carrying cytoplasmic activated prog rammed cell death 1 (PD1; PDCD1; CD279; programmed death-1), with potential antineoplastic activity. Upon intravenous administration, autologous cytoplasmic activated PD-1 CAR T-cells target, bind to, and induce selective toxicity in CD19-expressing tumor cells. The cytoplasmic activated PD1, a negative immunoregulatory human cell surface receptor, normally binds to programmed cell death-1 lig and 1 (PD-L1; cluster of differentiation 274; CD274) on tumor cells, causing T-cell inactivation. By preventing PD1/PD-L1 signaling, T-cell exhaustion is abrogated, and T-cell activation is enhanced leading to an increased cytotoxic T-lymphocyte (CT L)-mediated anti-tumor immune response ag ainst PD-L1expressing tumor cells. CD19 is a B-cell-specific cell surface antigen overexpressed in Bcell lineage tumors. 